International Journal of Oceans and Oceanography

ISSN 0973-2667 Volume 14, Number 1 (2020), pp. 109-124

(C) Research India Publications

https://dx.doi.org/10.37622/IJOO/14.1.2020.109-124

\title{
Computational Methods for Long Term Monitoring of New Production and f-ratio Variability in Bay of Bengal
}

\author{
D. Poornima ${ }^{1 *}$, R. Shanthi ${ }^{1}$, R. Ranith ${ }^{1}$, R.K. Sarangi ${ }^{2}$, \\ A. Saravanakumar ${ }^{1}$ and T. Thangaradjou ${ }^{1 \dagger}$ \\ ${ }^{1}$ Centre of Advanced Study in Marine Biology, Faculty of Marine Sciences, Annamalai \\ University, Parangipettai- 608502, Tamilnadu, India. \\ ${ }^{\dagger}$ Present Address: Science and Engineering Research Board (SERB), New Delhi, India. \\ ${ }^{2}$ Planetary Sciences and Marine Biology Division, Biological and Planetary Sciences and \\ Applications Group, Space Application Centre (ISRO), Ahmedabad - 380 015, Gujarat, India.
}

\begin{abstract}
MODIS Aqua derived primary production and sea surface temperature (SST) data are used for calculating the $\mathrm{f}$ ratio and new production using previously developed models. Developed models were validated with in-situ new production and $f$ ratio values from cruise dataset collected during September 2014. The regression between derived and bottle measured $P_{\text {new }}$ value showed $\mathrm{R}^{2}=0.553, \mathrm{SEE}= \pm 51.632, \mathrm{MNB}=-0.414$ and $\mathrm{RMSE}= \pm 266.398$. Similarly $\mathrm{f}$ ratio is validated with in-situ derived value showed the clear underestimation with a $\mathrm{R}^{2}=0.537, \mathrm{SEE}= \pm 0.016, \mathrm{MNB}=-0.560$ and $\mathrm{RMSE}= \pm 0.182$. The seasonal and inter-annual variation of primary production, $\mathrm{f}$ ratio and new production showed the clear seasonal pattern between the seasons. The high $\left(133.64 \mathrm{mgCm}^{-2} \mathrm{~d}^{-1}\right)$ and low $\left(31.69 \mathrm{mgCm}^{-2} \mathrm{~d}^{-1}\right)$ new production ranges are observed during premonsoon and summer seasons. The integrated primary production and $f$ ratio of all the seasons provides a significant $R^{2}=0.585$. This is used to estimate the total annual primary production of Bay of Bengal as $\sim 11 \%$. The minimum $\left(0.028 \mathrm{GTCyr}^{-1}\right)$ and maximum $\left(0.037 \mathrm{GTCyr}^{-1}\right)$ annual new production observed for the years of 2014 and 2006. In the entire processes of primary production, new production rate was less and it indicates Bay of Bengal largely as the regeneration based basin than the new production.
\end{abstract}

Keywords: New production, f ratio, Bay of Bengal, sea surface temperature (SST), MODIS Aqua, Primary production, validation and seasonal 


\section{INTRODUCTION}

Oceanic primary production (NPP) has two components that is new $\left(\mathrm{P}_{\text {new }}\right)$ and regenerated production $\left(\mathrm{P}_{\mathrm{r}}\right)$. $\left(\mathrm{NPP}=\mathrm{P}_{\text {new }}+\mathrm{P}_{\mathrm{r}}\right)$, new production $\left(\mathrm{P}_{\text {new }}\right)$ is the fraction of primary production $\left(\mathrm{P}_{\mathrm{T}}\right)$ that is supported by external or 'new' input of nutrients ${ }^{1}$. The remainder of the primary production is referred to as regenerated production and it depends on reduced nitrogen derived from the excretion of organism and microbial activity in the photic zone ${ }^{2}$. $\mathrm{P}_{\text {new }}$ is quantitatively equivalent to the organic matter that can be exported from the primary production in the euphotic zone ${ }^{3}$. New production estimations are the potential avenue for the removal of atmospheric carbon and nitrogen to the deep ocean and have important implications for studies of greenhouse effect ${ }^{4}$. Ratio of $\mathrm{P}_{\text {new }}$ to NPP, $\left(\mathrm{f}=\mathrm{P}_{\text {new }} / \mathrm{NPP}\right)$ is referred to as the $\mathrm{f}$ ratio and it is an asymptotic function of the magnitude of primary production and it has two important applications in biological oceanography i.e. sinking flux of particulate organic matter to the deep ocean ${ }^{5}$ and global biogeochemical cycles.

The total and new production is correlated in linear way and the relation can be expressed in terms of straight line ${ }^{6}$. New production is one of the most important conceptual models formulated in biological oceanography behind the term of 'biological pump'4. It is the processes of fixation of inorganic carbon in organic matter during photosynthesis, its transformation by trophodynamics, physical mixing transport and gravitational settlings ${ }^{3}$. In a steady state system this export of organic carbon and nitrogen must be balanced by an equivalent input back into the photic zone $^{7}$.

Bay of Bengal is of special interest to oceanographers due to its unique seasonal reversing of atmospheric forcing, closed northern extent and representing high fresh water inputs and total suspended solids through perennial rivers. The first in-situ ${ }^{15} \mathrm{~N}$ based new production study in Bay of Bengal is carried out by Kumar et al. (2004) ${ }^{6}$. Besides this there are only few studies on new production estimation in the region and new production estimation based on compound remote sensing is lacking for the region. Remote sensing has been successfully used in biological oceanography for measuring properties that have a particular expression in the electromagnetic spectrum $^{8}$. Synoptic mapping of new production is an important requirement of global biogeochemical studies ${ }^{9}$ that can be possible only through the use of remotely sensed data. In the present study, an attempt has been made to check the accuracy of the computed algorithms of $\mathrm{P}_{\text {new }}$ and $\mathrm{f}$ ratio with the in-situ data collected from the southwest Bay of Bengal. Although, the description of the temporal and spatial variability of $\mathrm{P}_{\text {new }}$ and $\mathrm{f}$ ratio was attempted so as to get an idea of the variability of the flux of organic matter on the surface layer of Bay of Bengal.

\section{MATERIALS AND METHODS}

\section{Satellite data}

Different methods are proposed for retrieving new production from space born, SST, chlorophyll, nitrate, MLD, f ratio etc. However, present study used sea surface 
temperature and primary production (NPP) derived from satellite data for retrieving $\mathrm{f}$ ratio and new production. For this study, MODIS Aqua seasonal composites derived from monthly composites of primary production and seasonal composites of SST with a spatial resolution of $\sim 9 \mathrm{~km}$ for the period of 2002 to 2014 were retrieved from MODIS website http://modis.gsfc.nasa.gov. The seasonal images were categorized as (1) postmonsoon (January-March), (2) summer (April-June), (3) premonsoon (JulySeptember) and (4) monsoon (October-December) seasons. The data were further processed using ERDAS IMAGINE 9.2 and ENVI 4.7 version software for interpretation. The data sets were applied to geometric correction to remove the image distortions and bring them to a standard geographic projection (Lat/Lon) with modified Everest Datum.

\section{N-uptake measurements}

In the present study, nitrogen uptake rates were measured on board CRV Sagar Purvi during premonsoon season of 2014 (27 September to 2 October 2014). The samples are collected at surface of the water column for remote sensing based new production algorithm development along the southwest Bay of Bengal (Fig.1). Individual seawater samples were taken in polycarbonate bottles for measurement of nitrate (2L), ammonium (2L) and urea (1L) uptake rates. Followed by this, (99 atom \%) ${ }^{15} \mathrm{~N}$ $\mathrm{Na}^{15} \mathrm{NO}_{3},{ }^{15} \mathrm{NH}_{4} \mathrm{Cl}$ and $\mathrm{CO}\left({ }^{15} \mathrm{NH}_{2}\right)$ obtained from SIGMA ALDRICH, USA tracers added to the individual samples taken for the measurement of nitrate, ammonia and urea uptake rates respectively. Samples were also collected at each station for blank corrections for all the tracers. The amount of nitrate tracer added corresponded to less than $10 \%$ of the ambient nitrate concentration and $0.01 \mu \mathrm{M}$ of ammonium and urea tracers were added to the respective bottles following Watts and Owens ${ }^{10}$. After the addition of tracer, the samples were incubated for $4 \mathrm{hrs}$ symmetrical to the local noon on the deck.

All samples were filtered through $47 \mathrm{~mm}$ diameter and $0.7 \mu \mathrm{m}$ pore size Whatman $\mathrm{GF} / \mathrm{F}$ filters, then dried in an oven at $60^{\circ} \mathrm{C}$ overnight and brought to the shore for mass spectrometric analysis. For blank correction, zero time enrichment was estimated. The same concentrations of isotopically enriched tracers as in samples were added to the blank also. Immediately after the addition, these samples were filtered and dried for blank determination. The samples were analysed using elemental analyser. The particulate organic nitrogen (PON) of the water samples were analyzed using CHNS/O analyzer (Perkin elmer 2400). Uptake rates were analyzed using the equation of Dugdale and Wilkerson ${ }^{11}$. The total $\mathrm{N}$-uptake rate was then calculated as a sum of nitrate, ammonium and urea uptake rates and f-ratio as a ratio of nitrate uptake to the total $\mathrm{N}$-uptake. 


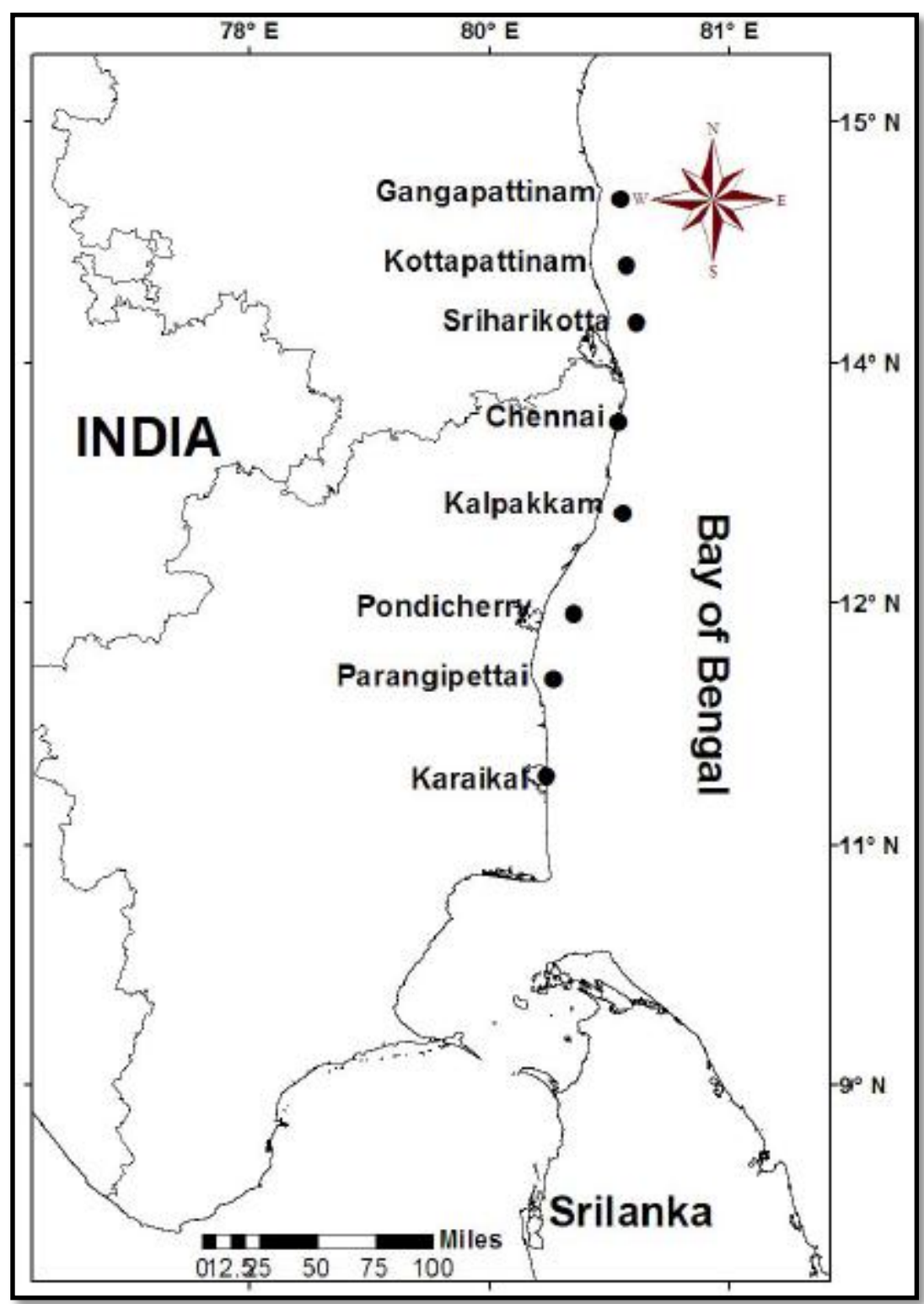

Fig. 1. Map showing the study area

\section{Computation of 'f' ratio and new production $\left(P_{n e w}\right)$}

Usually, $\mathrm{f}$ ratio will be calculated as the ratio of phytoplankton nitrogen assimilation to the sum of nitrate, ammonium and urea assimilation $(1,5)$. Laws et al. $(2011)^{12}$ proposed simple equation using SST and NPP as independent variables to estimate ratios of export to primary production from satellite derived SST and primary production. Using this model satellite derived estimates of SST and primary production (MODIS Aqua) estimates of $\mathrm{f}$ ratio and new production was made. The fraction of total primary production that is exported to deep layers in the form of POC or DOC is quantified by the export ratio (f). In the steady state, new production 
which is equal to primary production minus heterotrophic, is equivalent to the organic carbon (export production) from euphotic zone ${ }^{13}$.

$$
f=0.04756 *(0.78)-\{0.43 \times(S S T) \mid 30\} * N P P^{0.307}
$$

$\mathrm{f}$ - $\mathrm{f}$ ratio, SST- Sea surface temperature and NPP - Integrated Net primary production

After computing the f ratio with the help of SST and NPP, new production was then calculated by using the equation proposed by Sathyendranath et al. $(1991)^{14}$.

$$
P_{\text {new }}=f \times N P P
$$

From the above calculations, new production and $\mathrm{f}$ ratio in Bay of Bengal were estimated. New production was calculated as the product of the integrated primary productivity and model derived $f$ ratio. This calculation was carried out for every pixel for every season.

\section{STATISTICAL ANALYSIS}

\section{Subset and transect data retrieval}

The study focused for the Bay of Bengal to know the seasonal mean and standard deviation of satellite derived primary production, $\mathrm{f}$ ratio and new production concentration. The pixel/data points falling in the box of concurrent, latitude: $10.8^{\circ}$ $19.5^{\circ} \mathrm{N} /$ longitude: $79.5^{\circ}-85.5^{\circ} \mathrm{E}$ was taken for new production and $\mathrm{f}$ ratio calculation. The pixel/data points falling within the pockets were used to generate the mean and standard deviation of the respective seasonal composites of primary production, $f$ ratio and new production concentration by using ENVI 4.7 software. Seasonal mean and standard deviation data for each dataset were plotted as bar plots to understand the variability in respective time scale and seasons.

\section{RESULTS}

\section{Validation of seasonal new production and $f$ ratio maps}

A statistical comparison of the computed $f$ ratio and new production data was made by using in-situ analysis. Validation of $\mathrm{f}$ ratio and new production showed a significant positive relationship between the computed $\mathrm{P}_{\text {new }}$ and in-situ data with a $\mathrm{R}^{2}=0.553, \mathrm{SEE}= \pm 51.632, \mathrm{MNB}=-0.414$ and $\mathrm{RMSE}= \pm 266.398$ (Fig. 2). For $\mathrm{f}$ ratio, validation of in-situ and modeled $\mathrm{f}$ ratio generated by using both MODIS-Aqua derived SST and integrated primary production showed clear under estimation with $\mathrm{R}^{2}=0.537, \mathrm{SEE}= \pm 0.016, \mathrm{MNB}=-0.560$ and $\mathrm{RMSE}= \pm 0.182$ (Fig.3). Both validations gives the negative mean normalized bias between the models and derived new production and $\mathrm{f}$ ratios indicating the underestimation of model derived values. 


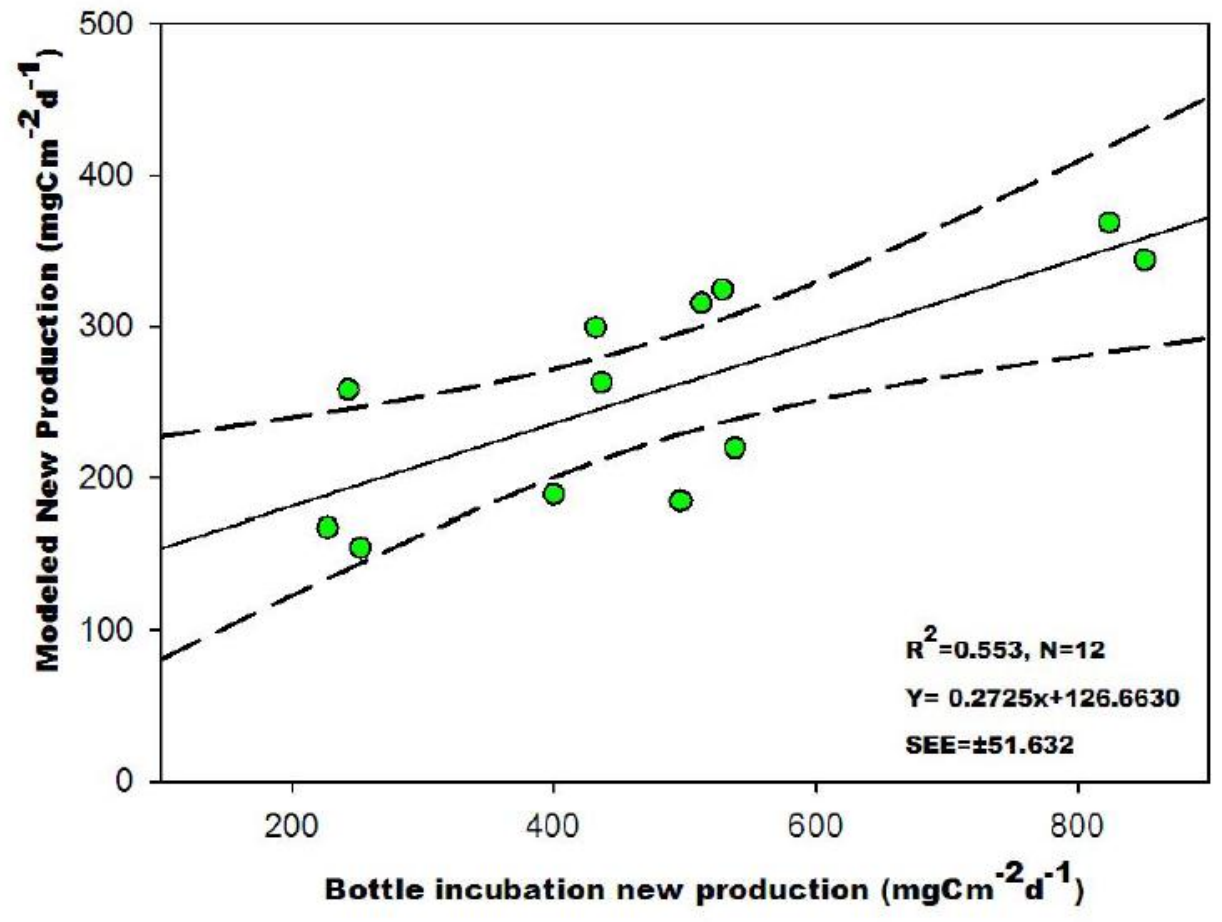

Fig. 2. Comparison of bottle incubation $P_{\text {new }}$ Vs modeled $P_{\text {new }}$

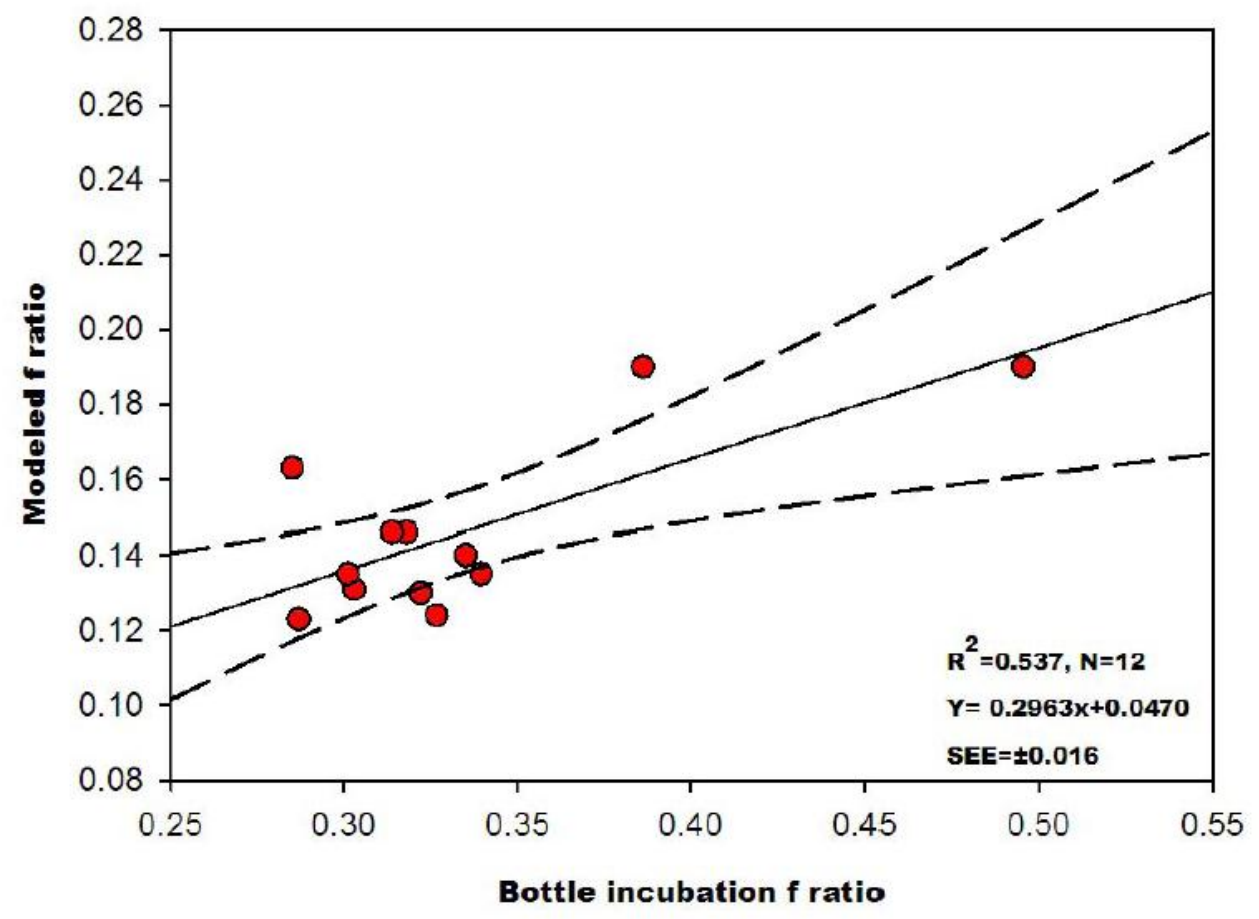

Fig. 3. Comparison of bottle incubation $f$ ratio Vs modeled $f$ ratio 


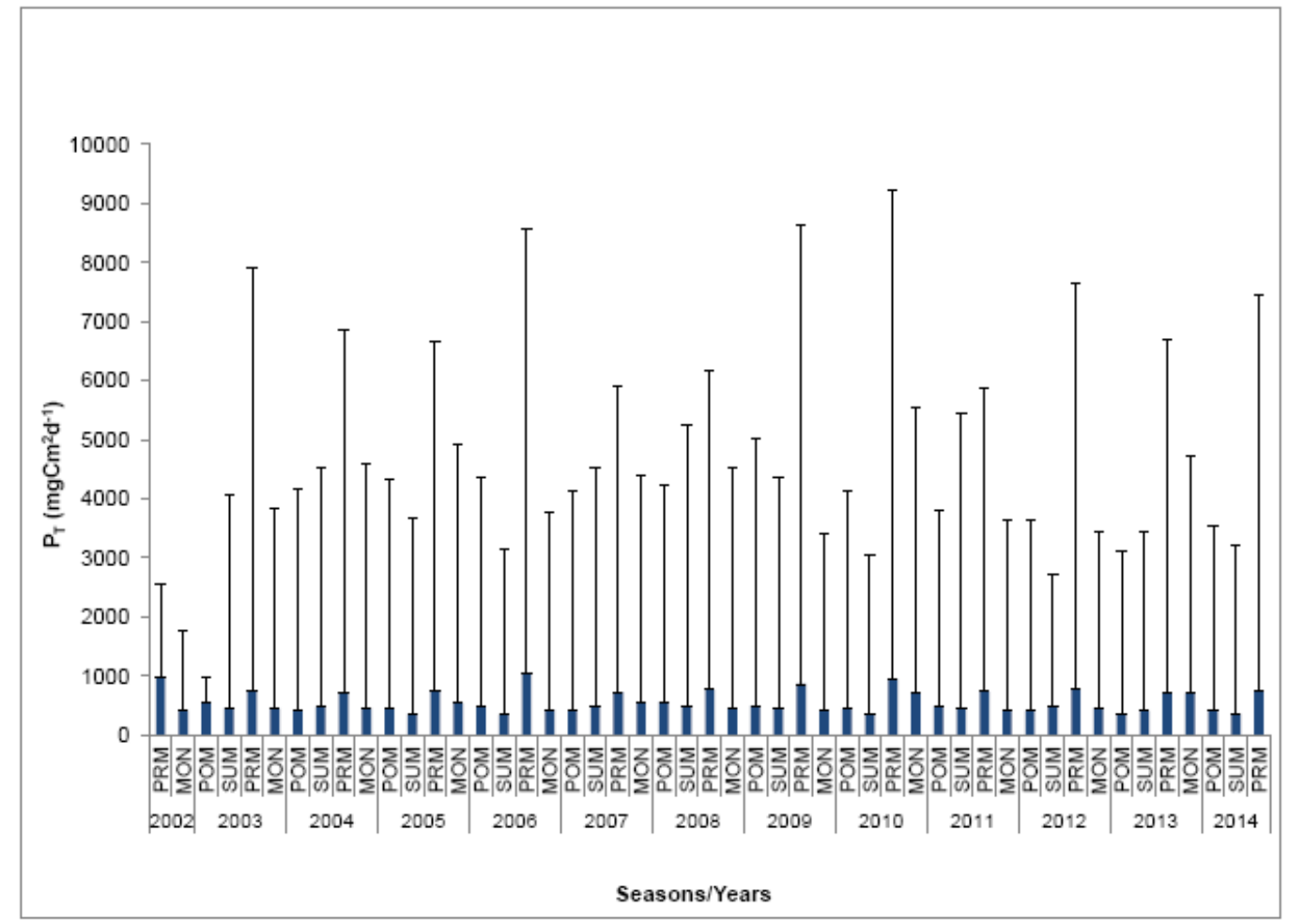

Fig. 4. Seasonal and inter-annual variability of primary productivity $\left(\mathrm{P}_{\mathrm{T}}\right)$ recorded for the period of 2002-2014

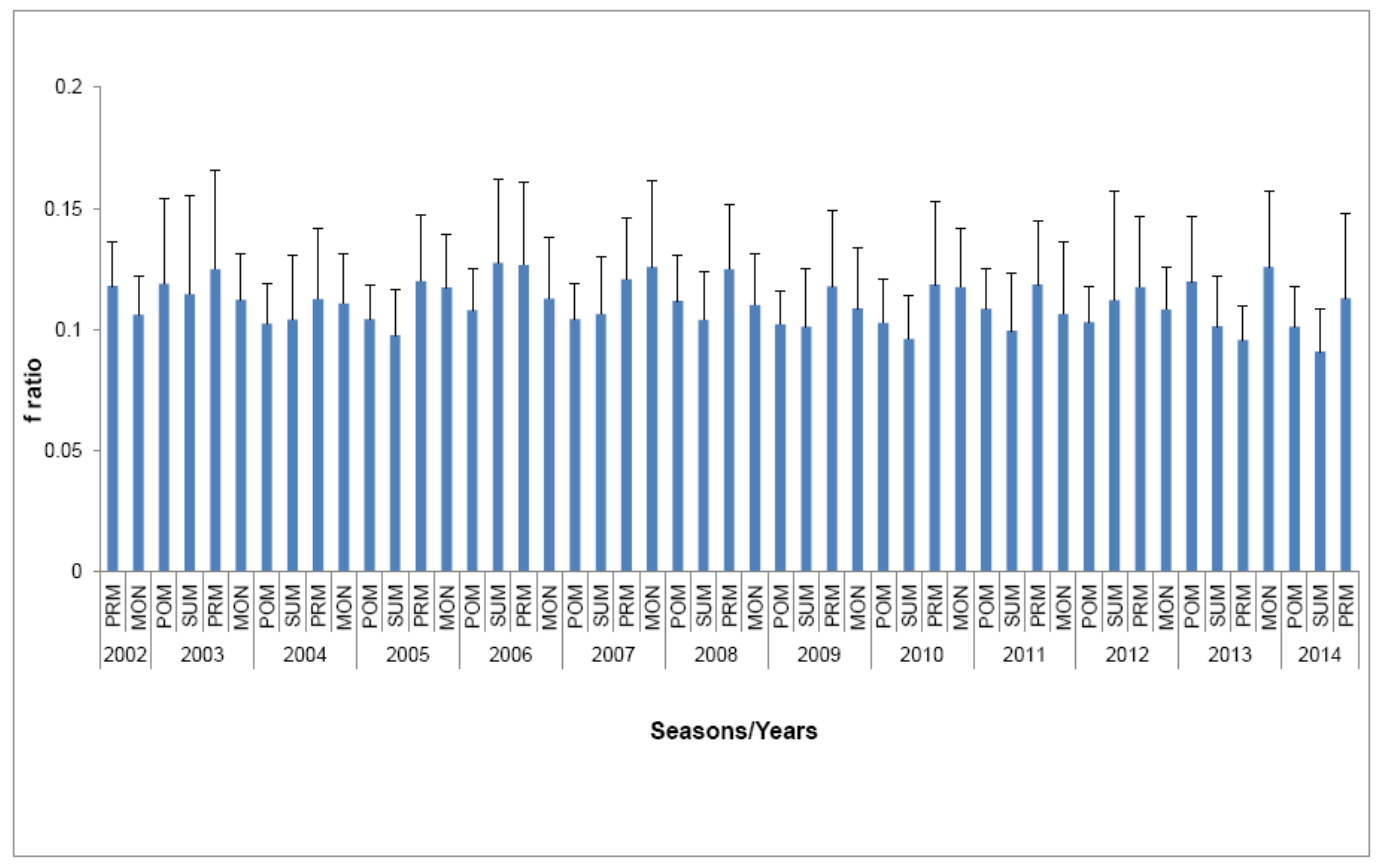

Fig. 5. Seasonal and inter-annual variability of modeled $f$ ratio recorded for the period of 2002-2014 


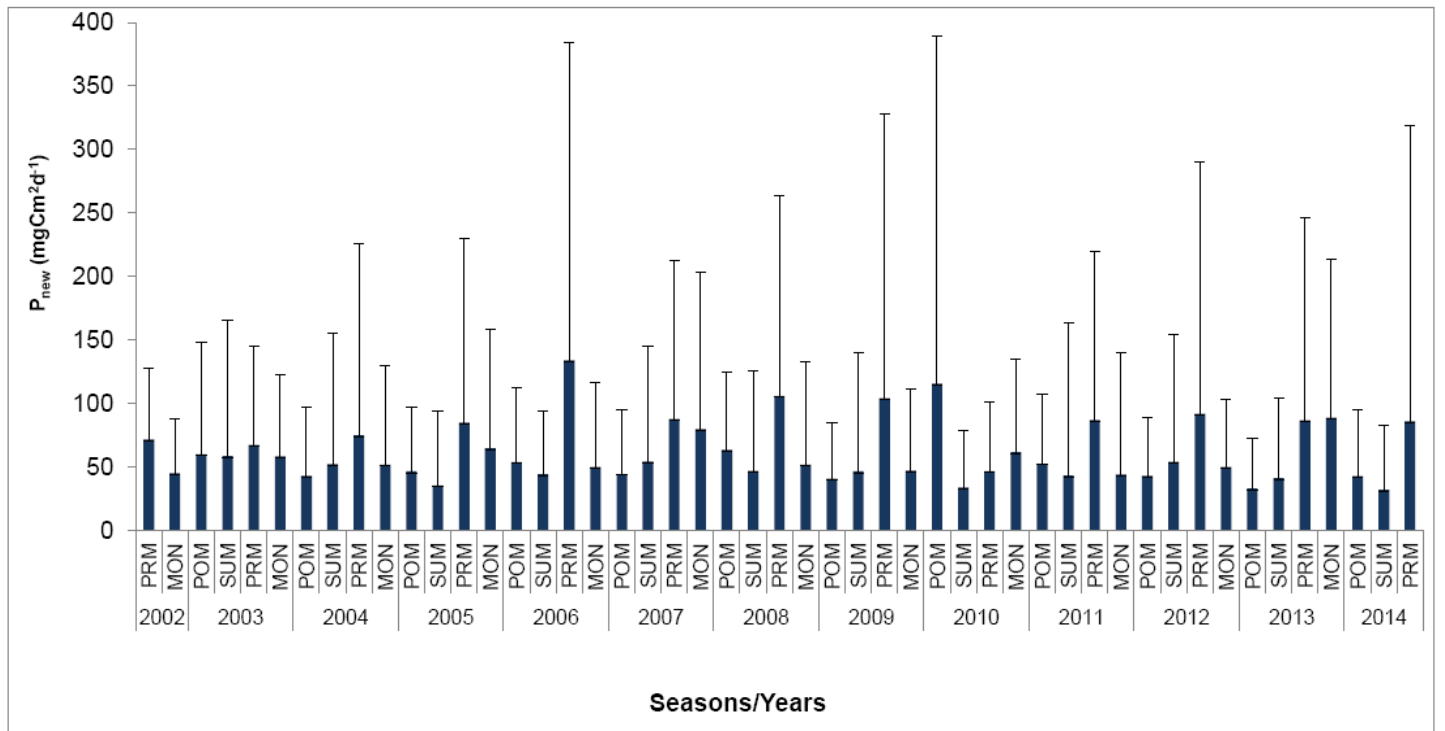

Fig. 6. Seasonal and inter-annual variability of modeled new production $\left(\mathrm{P}_{\text {new }}\right)$ recorded for the period of 2002-2014

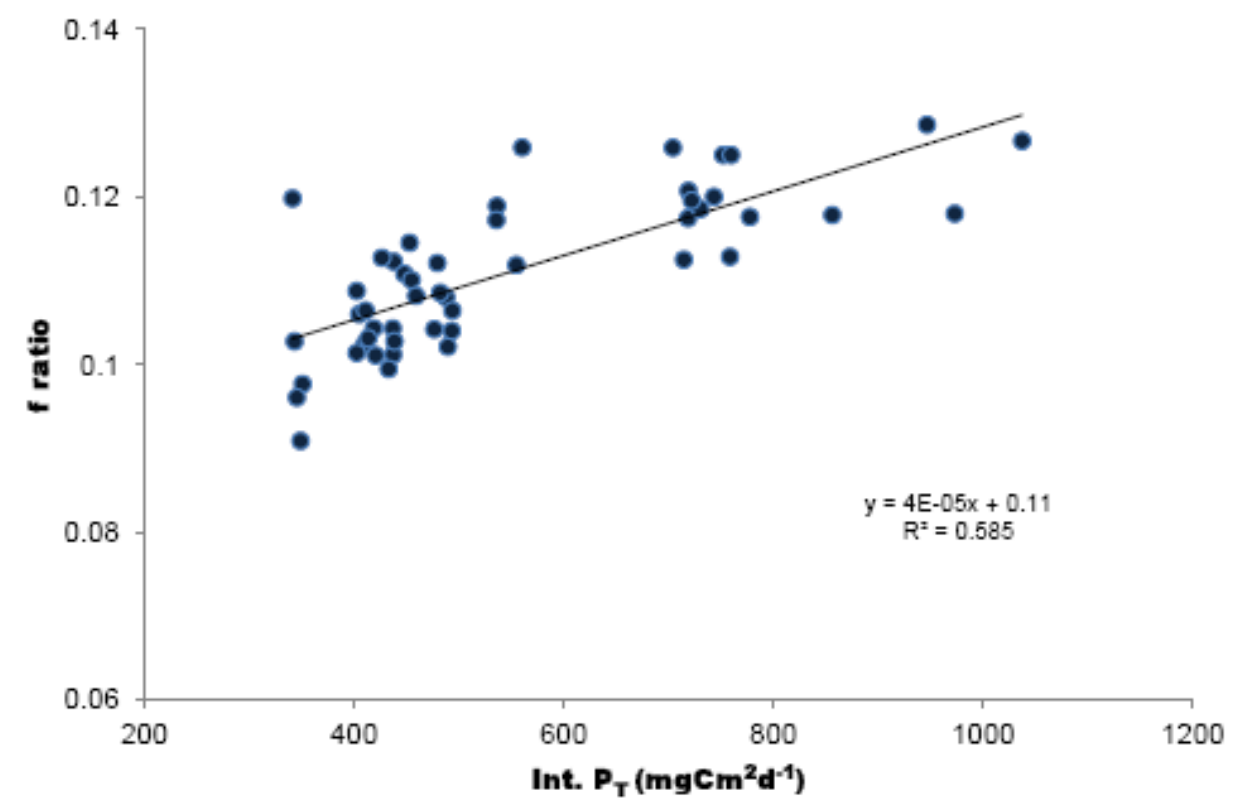

Fig. 7. Regression analysis of integrated primary production and f ratio 


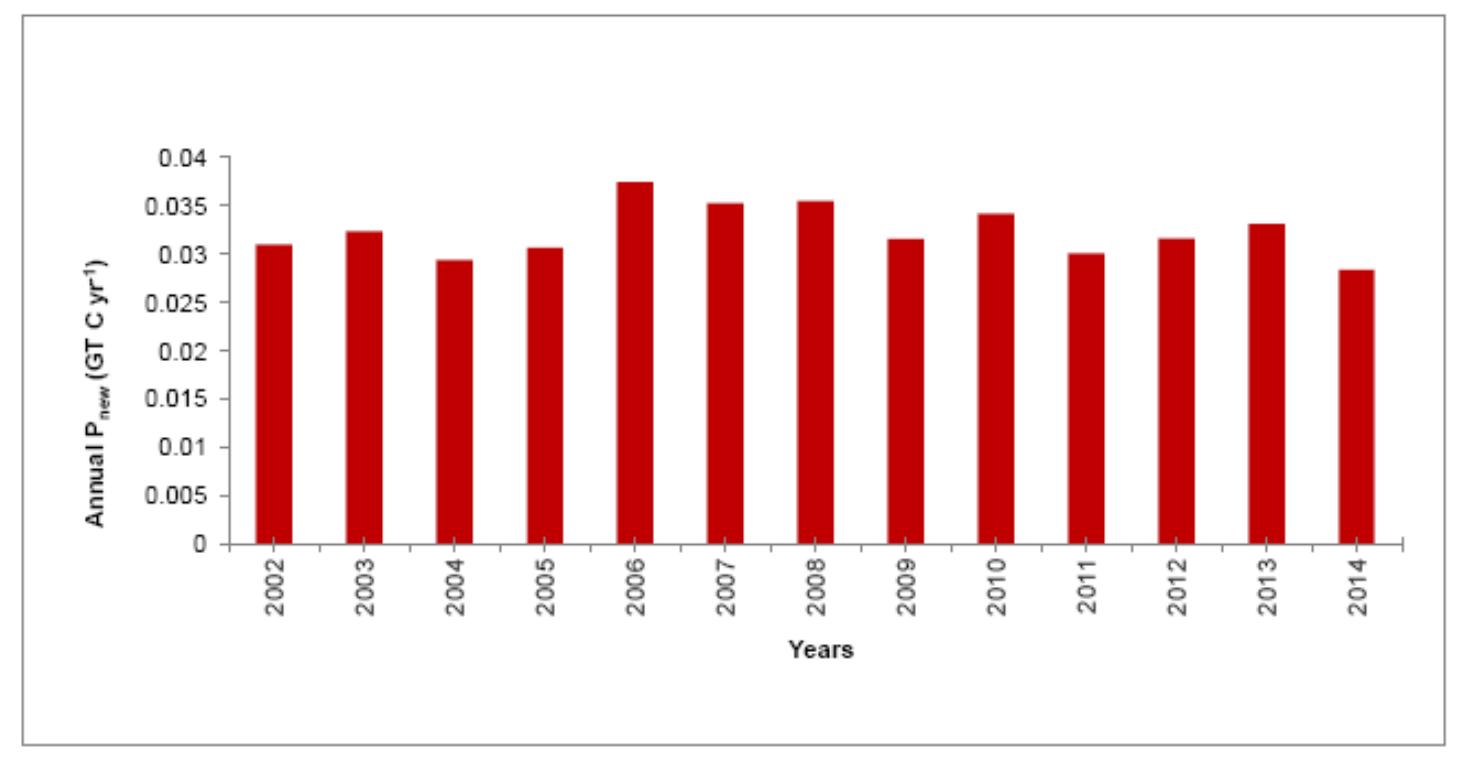

Fig. 8. Annual new production recorded for the period of 2002-2014

\section{Interpretation of seasonal and interannual variation of primary production, $f$ ratio and new production}

The minimum (341.076 $\left.\mathrm{mgCm}^{2} \mathrm{~d}^{-1}\right)$ and maximum $\left(1037.085 \mathrm{mgCm}^{2} \mathrm{~d}^{-1}\right)$ mean integrated primary production were registered during postmonsoon (2013) and premonsoon (2006) seasons respectively (Fig. 4). The mean trend of the seasonal integrated primary production is summer $>$ postmonsoon $>$ monsoon $>$ premonsoon. As the primary production in the bay varies spatially and temporally the standard deviation values are quite higher than the mean values.

Fig.5 indicates the seasonal variability of $\mathrm{f}$ ratio in the southwest Bay of Bengal with the highest $f$ ratio (0.13) during monsoon (2013) and the lowest (0.09) was observed during summer (2014) seasons. The dispersion of the f values was similar throughout the Bay of Bengal only slight variation was observed along the coastal regions. The mean trend of the seasonal $f$ ratio is in the order of summer $>$ postmonsoon $>$ premonsoon $>$ monsoon seasons.

The seasonal new production was high (133.64 $\left.\mathrm{mgCm}^{2} \mathrm{~d}^{-1}\right)$ during premonsoon season (2006) and the lowest was recorded (31.69 $\left.\mathrm{mgCm}^{2} \mathrm{~d}^{-1}\right)$ in the summer 2014 (Fig.6). Overall, new production for the region for premonsoon period was $86.48 \mathrm{mgCm}^{2} \mathrm{~d}^{-1}$ which is almost twice the mean value observed for the summer season $(44.88$ $\left.m g C m^{2} \mathrm{~d}^{-1}\right)$. The mean trend of the seasonal integrated new production is summer> postmonsoon> monsoon> premonsoon seasons.

\section{Comparison of primary production Vs f ratio}

The relationship between primary productivity and f ratio (Fig. 7) indicates higher $\mathrm{f}$ ratio for higher total productivity, emphasizing the substantial role that nitrate plays in 
the primary production. The curve fit shows the significant linear relationship with $\mathrm{R}^{2}=0.58$ and was described by the equation: $\mathrm{Y}=4 \mathrm{E}^{-05 *} \mathrm{X}+0.11$, where $\mathrm{Y}=$ integrated $\mathrm{f}-$ ratio and $\mathrm{X}=$ integrated primary production $\left(\mathrm{mgCm}^{2} \mathrm{~d}^{-1}\right)$. Annual new production showed minimum (0.028 GT C $\left.\mathrm{yr}^{-1}\right)$ production during 2014 and maximum (0.037 GT $\mathrm{C} \mathrm{yr}^{-1}$ ) observed during 2006 (Fig. 8). From the space born estimates of integrated primary production and $\mathrm{f}$ ratio, it is estimated that the total annual primary production for the Bay of Bengal is $11 \%$ which is calculated from the equation of a straight line, ' $\mathrm{m}$ ' represents the gradient and ' $c$ ' represents the ' $y$ ' intercept. Intercept of the ' $\mathrm{Y}$ ' denotes that $\mathrm{f}$ ratio was 0.11 .

\section{DISCUSSION}

Present study attempted to develop $\mathrm{f}$ ratio and new production estimation based on the algorithm originally developed for use with satellite remote sensing data. It is derived from a model initially described by Laws et al. (2011) ${ }^{12}$, which estimates new production based on changes in physical as well as biological status of the phytoplankton assemblage, and corresponding changes in nitrogen utilization ${ }^{(15,16)}$.

Measuring NPP and $\mathrm{P}_{\text {new }}$ with bottle incubation experiment using compounds labeled with ${ }^{14} \mathrm{C}$ and ${ }^{15} \mathrm{~N}$ respectively is complicated and time consuming and only get very limited number of data with low spatial and temporal coverage. More over the incubation period in mid oceans, sampling at hard weather condition, sophisticated instrumentation facilities, access to the facilities and cost estimates often curtails the field observations to the limited number of points and lacks spatial and temporal coverage. Hence, in the present study new production is attempted to estimate from the remotely sensed primary productivity and f ratio. Remotely sensed data of SST and primary production yield more representative estimates of the large scale average production than those calculated from ship data alone ${ }^{14}$. A comparison of depth integrated bottle measurements using the stable isotope ${ }^{15} \mathrm{~N}$ provides a significant relationship, as an indicator of surface new production estimate. The regression between observed and predicted data using the surface values and the depth integrated values showed significant $\mathrm{R}^{2}$ value. The results are similar to that of previous reports ${ }^{17}$. Comparing these results is often complex as the satellite data represents the composites of many pixels scanned on a single day, month and seasonal and in-situ estimates are based on a handful of stations covered for a period. As well as the effect of clouds obscuring the sea surface could be important in biasing the estimates of new production $^{18}$. The determination of modeled new production SEE $= \pm 65.266$, RMSE $=$ 214.426 and $\mathrm{MNB}=-0.114$ does not provide the linearity between the observed and predicted values as it is reported by Neter et al. (1990) ${ }^{18}$ but contradict result observed by Dugdale et al. (1989) ${ }^{20}$ in satellite derived values of mean depth integrated $p \mathrm{NO}_{3}$ were also greater than shipboard values at Cap Blanc.

There is more number of new production and f ratio models available for various regions, chlorophyll concentration as the best indicator of new production in the equatorial Atlantic Ocean ${ }^{21}$. While $f$ ratio expressed as the function of $\mathrm{N}$ (nitrogen) ${ }^{22}$. Eppley and Peterson ${ }^{5}$ expressed the nonlinear relationship exists between $\mathrm{f}$ ratio and 
NPP and also confirmed by other regions. Sathyendranath et al. ${ }^{14}$ estimated the $f$ ratio from the relationship between Nitrate $(\mathrm{N})$ and Temperature $(\mathrm{T})$ and between $\mathrm{f}$ ratio ( $\mathrm{f}$ ) and nitrate $(\mathrm{N})$. Sea surface temperature has been used as a proxy to model surface nitrate distributions as well as total and new production ${ }^{23}$. F ratio versus sea surface temperature and surface nitrate concentrations always shows considerable relationships ${ }^{(24,22) .}$ Hernández-de-la-Torre et al. ${ }^{25}$ developed the empirical algorithms for $\mathrm{f}$ ratio and NPP by using empirical algorithms based on in-situ nitrate and temperature data. Watts et $\mathrm{al}^{4}$ developed an empirical algorithm for estimating the $\mathrm{f}$ ratio by logarithmic relationship observed between the bottle incubation derived $\mathrm{f}$ ratio and total primary production in the northwest Indian Ocean region. The dispersion of ' $\mathrm{f}$ ' ratios displays a very similar range of variation. Based on the analysis of a very large set of measured new production rates in the Bay of Bengal, Reuer et al. ${ }^{26}$ suggests that an approximately constant fraction of carbon net primary production is exported as equal to 0.11 .

The present investigation clearly denotes the high and low new production, primary production as well as $\mathrm{f}$ ratio are recorded during premonsoon and summer seasons respectively. Overall the averaged new production of premonsoon is twice than the average of summer. Similarly Kumar et al. ${ }^{6}$ also reported the high new production during premonsoon season. The seasonal maps clearly indicate the high concentration of productivity along the nearshore region of Bay of Bengal. This has led to the speculation the rivers draining into Bay of Bengal do not provide nitrate to the oceans apparently gets consumed in the estuary and coast itself $^{12}$. Perhaps during premonsoon season, Bay of Bengal reported with such intense upwelling at $40 \mathrm{~km}$ wide band along the western margin (east coast of India) largely because of the local long shore wind stress $^{27}$. Apart from the upwelling, wind driven turbulent mixing is another phenomenon that can inject nutrients in the upper layer of the ocean. Low productivity was observed during the summer season due to strong stratification of the surface layer. The weak winds over Bay of Bengal are insufficient to erode the stratified layer ${ }^{28}$.

Present measurements during premonsoon season showed higher levels of primary production $\left(1072.836 \mathrm{mg} \mathrm{Cm}^{2} \mathrm{~d}^{-1}\right)$. Which is lower than integrated bottle measurements $\left(1666 \mathrm{mg} \mathrm{Cm}^{2} \mathrm{~d}^{-1}\right)$ in the northwest Indian Ocean ${ }^{4}$. Kumar and Ramesh $^{29}$ estimated the total productivity in the Bay of Bengal during fall intermonsoon ranged from 90 to $875 \mathrm{mg} \mathrm{Cm}^{2} \mathrm{~d}^{-1}$ with an average of $316 \mathrm{mg} \mathrm{Cm}^{2} \mathrm{~d}^{-1}$. This is 2.5 times lower than the Arabian Sea values $\left(\sim 800 \mathrm{mg} \mathrm{Cm}^{2} \mathrm{~d}^{-1}\right)$ reported by Bhattathiri et al. ${ }^{30}$. The average value $\left(554.73 \mathrm{mg} \mathrm{Cm}^{2} \mathrm{~d}^{-1}\right)$ during the present study is greater than the value $\left(316 \mathrm{mg} \mathrm{Cm}^{2} \mathrm{~d}^{-1}\right)$ reported by Kumar and Ramesh ${ }^{29}$ largely due to the increased availability of nutrients during premonsoon season. Similar values was observed by Watts et al. ${ }^{4}$ developed primary productivity $\left(\sim 540 \mathrm{mg} \mathrm{Cm}^{2} \mathrm{~d}^{-1}\right)$ model for calculating new production in the northwest Indian Ocean but new production estimation map showed higher $\left(\sim 200 \mathrm{mg} \mathrm{Cm}^{2} \mathrm{~d}^{-1}\right)$ values than the present study ( $\left.\sim 38.33 \mathrm{mg} \mathrm{Cm}^{2} \mathrm{~d}^{-1}\right)$. This is largely due to the bias in computation of $\mathrm{f}$ ratio which provides very less range of distribution so the resultant new production also underestimates the actual and is evidenced by regression analysis of bottled 
experiment and modeled $\mathrm{f}$ ratio. However, it indicates that the new production rate is comparatively less than the regenerated production by ammonia and urea. Sharada et al. ${ }^{31}$ also pointed out regenerated production is dominant for carbon fixation in large parts of the Bay of Bengal due to stratification effects. The biological processes increase the out gassing of $\mathrm{CO}_{2}$ in the Bay of Bengal during all seasons especially in the northeast monsoon season.

$F$ ratio of the Bay of Bengal resembles the oligotrophic condition of the Bay of Bengal with a mean $\mathrm{f}$ ratio of 0.11. Kumar and Ramesh ${ }^{29}$ showed $\mathrm{f}$ ratios to be ranging from 0.1 to 0.8 (mean $~ 0.5$ ) and this value is higher than the Arabian Sea (mean<0.3, 0.2 and 0.1) reported by Watts and Owens ${ }^{10}$; Sambrotto ${ }^{32}$; McCarthy et al. $^{33}$ and Olson et al. ${ }^{34}$. Contradict, Hidalgo-Gonzalez and Borrego ${ }^{35} \mathrm{f}$ ratio values are high for summer up to 0.64 but Eppley ${ }^{36}$ suggested that $f$ ratio of 0.1 for oligotrophic waters and 0.4 for rich coastal waters. The $f$ ratio is a measure of the capacity of the system to support production at higher trophic levels ${ }^{14}$. This indicates that the f ratio of Bay of Bengal estimated using this model is very low, so that, the present model need to be upgraded with more ship based measurements for day to day variability in the productivity.

The results of seasonal and inter-annual variability clearly explain the seasonal and interannual variations for $\mathrm{P}_{\text {new }}$ and NPP between the seasons and years. There is no clear inter-annual variation is observed in the $f$ ratio and new production maps. However, Kudela and Chavez ${ }^{17}$ observed the effects of the 1997-1999 El Nino/La Nina using a physiologically based algorithm (Temperature and biomass) for the Moterey Bay, California and observed notable decrease in new production values during the El Nino event and a corresponding enhancement during La Nina period. Hernández-de-la-Torre et al. ${ }^{25}$ analysed the new production using remote sensing techniques from 1977 to 1998 which retrieved frequent negative new production values while the years of 1999-2002 showed positive values because of inter-decadal regime shifts. Karl et al. ${ }^{37}$ showed an 11-year time series of the ratio of sinking flux to primary production for the Bermuda (0.02-0.21) and Hawaii (0.02-0.15). The effect of clouds obscuring the sea surface could cause the bias in the estimation of new production is the major problem in the Bay of Bengal.

\section{CONCLUSION}

Remote sensing based measurements are best for multiyear average, suitable for climate change and biogeochemical cycles. In this context, present study retrieved the annual new production and $\mathrm{f}$ ratio by remote sensing which seems to be the only solution to solve the climate change studies. The smaller variation of $\mathrm{f}$ ratios and new production for the Bay of Bengal makes it difficult to capture adequately the large spatial and temporal variability of biological production in the Bay of Bengal. The $9 \mathrm{~km}$ data also used to make the map little corner by missing several small-scale eddies and upwelling which are rare features in Bay of Bengal. The quantum of new production is comparatively less than the northwest Indian Ocean region, as Bay of Bengal is dominant by regenerated production. For future analysis in the Bay of 
Bengal, ${ }^{15} \mathrm{~N}$ parallel with ${ }^{14} \mathrm{C}$ incubations and nutrient determinations are needed for the Bay of Bengal to better characterize the parameters used in algorithms. The contribution of Bay of Bengal to the total new production of northern Indian Ocean is very low and it is high for its western counterpart of Arabian Sea.

\section{ACKNOWLEDGMENT}

Authors are thankful Director and Dean, Centre of Advanced Study in Marine Biology, Faculty of Marine Sciences and the authorities of Annamalai University for their support and encouragement during the course of study/project as part of the Meteorology and Oceanography (MOP-2) Program of ISRO. Authors also thank the Space Applications Centre, Ahmedabad (MOP- II budget code: 0303650RM701) for funding and providing facilities for carrying out the work. The contents and views reported in this manuscript are of individual authors and not reflect the views and positions of the institutions they belong.

\section{REFERENCES}

[1] Dugdale R.C., and Goering, J.J., 1967, "Uptake of new and regenerated forms of nitrogen in primary productivity," Limnol. Oceanogr., 12(2), 196-206.

[2] Platt, T., Jauhari, P., and Sathyendranath, S., 1992, "The importance and measurement of new production," In: Falkowski, P.G., and Woodhead, A.D., (Eds.), Primary productivity and biogeochemical cycles in the sea, New York, pp. 273-284.

[3] Hidalgo-Gonzalez, R.M., Alvarez-Borrego, S., Fuentes-Yaco, C., and Platt, T., 2005, "Satellite derived total and new phytoplankton production in the Gulf of Mexico," Indian J. Mar. Sci., 34(4), 408-417.

[4] Watts, L.J., Sathyendranath, S., Caverhill, C., Maass, H., Platt, T., and Owens, N.J.P., 1999, "Modelling new production in the north- west Indian Ocean region," Mar. Eco. Pro. Ser., 183, 1-12.

[5] Eppley R.W., and Peterson, B.J., 1979, "Particulate organic matter flux and planktonic new production in the deep ocean," Nature, 282(5740), 677-680.

[6] Kumar, S., Ramesh, R., Bhosle, N.B., Sardesai, S., and Sheshshayee, M.S., 2004, "Natural isotopic composition of nitrogen in suspended particulate matter in the Bay of Bengal," Biogeosci., 1, 63-70.

[7] Williams, N., 1998, "The Mediterranean beckons to Europe's oceanographers," Science, 279, 483-484.

[8] Platt, T., Jauhari, P., and Sathyendranath, S., 1991, "The importance and measurement of new production". In: Falkowski, P.G., and Woodhead, A.D. (Eds.), Primary productivity and biogeo- chemical cycles in the sea, pp. 273284. Plenum Press, New York. 
[9] Platt, T., Harrison, W.G., Lewis, M.R., Li, W.K.W., Sathyendranath, S., Smith, R.E., and Vezina, A.F., 1989, "Biological production of the oceans: Estimating new production in the sea," The case for a consensus, Mar. Eco. Pro. Ser., 52, 77-88.

[10] Watts, L.J., and Owens, N.J.P., 1999, "Nitrogen assimilation and f ratio in the northwestern Indian Ocean during an intermonsoon period," Deep Sea Res. II, $46,725-743$.

[11] Dugdale, R.C., and Wilkerson, F.P., 1986, "The use of ${ }^{I 5} \mathrm{~N}$ to measure nitrogen uptake in eutrophic oceans; experimental considerations," Eppley, R.W., 1981 Relations between nutrient assimilation, Limnol. Oceanogr., 31573-689.

[12] Laws, E.A. D’Sa, E., and Naik, P., 2011, "Simple equations to estimate ratios of new or export production to total production from satellite derived estimates of sea surface temperature and primary production," Limnol. Oceanogr., 9, 593-601.

[13] Merlivat, L., Boutin, J., and Antoine, D., 2015, "Roles of biological and physical processes in driving seasonal air-sea $\mathrm{CO}_{2}$ flux in the southern ocean: new insights from CARIOCA pCO ${ }_{2}$, J. Mar. Sys., 147, 9-20.

[14] Sathyendranath, S., Platt, T., Horne, E.P.W., Harrison, W.G., Ulloa, O., Outerbridge, R., and Hoepffner, N., 1991, "Estimation of New Production in the Ocean by Compound Remote- Sensing, Nature," 353(6340), 129-133.

[15] Kudela, R.M., Cochlan, W.P., and Dugdale, R.C., 1997, "Carbon and nitrogen uptake response to light by phytoplankton during and upwelling event," J. Plankton Res. II., 19, 609-630.

[16] Kudela, R.M., and Dugdale, R.C., 2000, "Nutrient regulation of phytoplankton productivity in Monterey Bay, California,” Deep-Sea Res., II, 47, 1023-1053.

[17] Kudela, R.M., and Chavez, F.P., 2002, "Multi-platform remote sensing of new production in central California during the 1997-1998 El Nino," Prog. Oceanogr., 54, 33-249.

[18] Michaelson, J., Zhang, X., and Smith, R.C., 1988, "Variability of pigment biomass in the California Current system as determined by satellite imagery," J. Geophy. Res., 93, 10883-10896.

[19] Neter, J., Wasserman, W., and Kutner, M.H., 1990, “Applied Linear Statistical Models,” 3rd Ed, Irwin, Boston, MA.CRC Press. ISBN 13: 9780256083385.

[20] Dugdale, R.C., Morel, A., Bricaud, A., and Wilkerson, F.P., 1989, "Modeling new production in upwelling centers: A case study of modeling new production from remotely sensed temperature and color," J. Geophy. Res., 94(18), 119-132.

[21] Bouteiller Le, A., 1986, "Environment control of nitrate and ammonium uptake by phytoplankton in the Equatorial Atlantic Ocean," Mar. Ecol. Prog. Ser., 30, 167-179. 
[22] Harrison W.G., Platt, T., and Lewis, M.R., 1987, "f-Ratio and its relationship to ambient nitrate concentration in coastal waters," J. Plankton Res., 9, 23524.

[23] Dugdale, R.C., Davis, C.O., and Wilkerson, F.P., 1997, “Assessment of new production at the upwelling center at Point Conception, California, using nitrate estimated from remotely sensed sea surface temperature," J. Geophy. Res., 102(4) , 8573-8585.

[24] Elskens, M., Goeyens, L., Dehairs, F., Rees, A., Joint, I., and Baeyens, W., 1999, "Improved estimation of f-ratio in natural phytoplankton assemblages," Deep Sea Res., 46, 1793-1808.

[25] Hernández-de-la-Torre, B., Gaxiola-Castro, G., Alvarez-Borrego, S., GómezValdéz, J., and Nájera-Martínez, S., 2003, "Inter-annual variability of new production in the southern region of the California Current," Deep-Sea Res-II., $50,2423-2430$.

[26] Reuer, M.K., Barnette, B.A., Bender, M.L., Falkowski, P.G., and Hendricks, M.B., 2007, "New estimates of Southern Ocean biological production rates from O2/Ar ratios and the triple isotope composition of O2," Deep Sea Res., 54(6), 951-974.

[27] Shetye, S.R., Gouveia, A.D., Shenoi, S.S.C., Sundar, D., Michael, G.S., Almeida, A.A., and Santanam, K., 1991, "The coastal currents off western India during north east monsoon," Deep Sea Res., 38, 1517-1529.

[28] Prasannakumar, S., Muraleedharan, P.M., Prasad, T.G., Gauns, M., Ramaiah, N., de Souza, S.N., Sardesai, S., and Madhupratap, M., 2002, "Why is the Bay of Bengal less productive during summer monsoon compared to the Arabian Sea?" Geophy. Res. Lett., 29(24), 2235.

[29] Kumar, S., and Ramesh, R., 2005, "Productivity measurements in the Bay of Bengal using ${ }^{15} \mathrm{~N}$ tracer: implications to the global carbon cycle," Indian J. Mar. Sci., 34(2), 153-162.

[30] Bhattathiri, P.M.A., Pant, A., Sawant, S., Gauns, M., Matondakar, S.G.P., and Mohanraju, R., 1996, "Phytoplankton production and chlorophyll distribution in eastern and central Arabian Sea in 1994-1995," Curr. Sci., 71, 857-862.

[31] Sharada, M.K., Swathi, P.S., Yajnik, K.S., and Kalyani Devasena, C., 2008, "Role of biology in the air-sea carbon flux in the Bay of Bengal and Arabian Sea,” J. Earth Sys. Sci., 117, 429-447.

[32] Sambrotto, R.N., 2001, "Nitrogen production in the northern Arabian Sea during the spring intermonsoon and Southwest monsoon seasons," Deep Sea Res. II., 48, 1173-1198.

[33] McCarthy, J.J., Garside, C., and Nevis, J., 1999, "Nitrogen dynamics during the Arabian Sea northeast monsoon,” Deep-sea Res. II., 46, 1623-1664.

[34] Olson, D.B., Hitchcock, G.L., Fine, R.A., and Warren, B.A., 1993, 
"Maintenance of low-oxygen layer in the Central Arabian Sea," Deep-sea Res. II., 40, 697-709.

[35] Hidalgo-González, R.M. and Álvarez-Borrego, S., 2004, "Total and new production in the Gulf of California estimated from ocean color data from the satellite sensor SeaWiFS," Deep-Sea Res., 51, 739-752.

[36] Eppley, R.W., 1992, "Chlorophyll, photosynthesis and new production in the Southern California Bight," Prog. Oceanogr., 30, 117-150.

[37] Karl, D.M., Bidigare, R.R., and Letelier., R.M., 2001, "Long-term changes in plankton community structure and productivity in the subtropical North Pacific Ocean: The domain shift hypothesis," Deep-Sea Res. II., 48, 14491470 . 